\title{
A Case Study: Understanding Non-Verbal Expressions When Learning Korean as a Foreign Language
}

\author{
Youn Ah Jung, Minkyung Yu \\ Florida State University, Tallahassee, USA
}

\begin{abstract}
The purpose of this study was to investigate what learners' non-verbal expressions were when they were learning a foreign language as Korean. The participants were Americans enrolled in Korean language class for 12-week session in southeastern church. Using qualitative research methods as a case study, the researchers investigated what learners used as non-verbal expressions when they were reflecting on their learning a foreign language. The data collected consisted of recording a video tape and transcribed what we observed during the sessions. The findings indicated that language learners used their non-verbal expressions as a tool of understanding and recognizing a foreign language, when they were reflecting their learning process. The study provided us an insight to understand what non-verbal expressions meant for novice language learners.
\end{abstract}

Keywords: foreign language learners, non-verbal expression, Korean language

\section{Introduction}

In broad terms, as defined by Eisenberg and Smith (1971, p. 20), non-verbal expressions are all forms communication except those that are coded in words. These communication forms include facial expressions, gestures, eye contact, interpersonal distance, and communicative meanings described by body language and gestures, such as yes/no, positive/negative, and successful/unsuccessful. Non-verbal communication between interlocutors in a foreign language situation poses importance in language difficulties to language learners. In particular, non-verbal expressions generally are less uncontrollable and more expressive for those with limited foreign language abilities who tend to be anxious, inept, and who avoid communicating in the target language (Koper, 1984). Non-verbal cues are a system used to aid language learners' linguistic expression. The combination of these communication features is often a subconscious choice made by speakers of a language group (Eryilmaz \& Darn, 2006).

Instructors' behaviors toward non-verbal cues relate to learners' classroom involvement. By using body language with verbal behavior, instructors enhance understanding of the topic (Sprinthall, 1994). Non-verbal communication impacts students' minds and behaviors toward a learning target and complements verbal behavior in the learning process. Non-verbal expressions generated by instructors are linked to learners' involvement in the learning process. Kodakos and Polemikos (2000) found that non-verbal relationships between the teacher and students were significant to classroom learning. Instructors who displayed at least one type of non-verbal expression in the classroom were more likely to encourage learners' participation in

Youn Ah Jung, Ph.D. candidate, graduate student, College of Eduction, Florida State University. Minkyung Yu, M.S., graduate student, College of Eduction, Florida State University. 
classroom activites and enhance their understanding and performance (Albers, 2001). Understanding non-verbal meanings displayed by low-proficient learners as they negotiate and attempt to generate oral language production gives instructors a starting point for instructional strategy. Instructors can then identify how low-proficient language learners communicate verbally and plan an instructional strategy to best link the learners' non-verbal cues to meaningful language learning processes. Non-verbal cues that are used as tools to send meaningful messages are created during the interaction between an instructor and learners who lack verbal communication abilities. How those non-verbal cues are meant and interpreted between language learners and instructor is important for that it can lead to effective language teaching approaches?

Unlike the extensive research in foreign language education, which examines multiple features of language learners' verbal language production, non-verbal communicational behaviors between language learners and their instructor have been rarely explored. Based on the assumption that, because their low level of proficiency and lack of language skills restrict them from producing oral language discourse, novice-level learners may need to use non-verbal linguistic cues as linguistic media to express thoughts and opinions during foreign language learning, this study examines whether language learners attempt to use non-verbal expressions to convey communicative meanings. If so, how these non-verbal expressions can be interpreted by the instructor and how the instructor responds to the language learners with respect to instructional strategies are also explored.

\section{Research Questions}

1. How do language learners use non-verbal expressions when they negotiate communicative skills?

2. How does the language instructor respond to leaners' non-verbal responses and utilize non-verbal expressions in his/her instruction?

\section{Methods}

\section{Ethnographic Inquiry}

While quantitative analysis utilizes measurement in terms of amount or frequency and seeks casual relationships, qualitative inquiry focuses on process and meaning (Denzin \& Lincoln, 2008). Since classic ethnographic research includes a detailed description of the whole of a culture, research engaging in ethnographic research occurs in the field where activity takes place and where ethnographers are able to produce thick written cultural descriptions from their observations. Current ethnographic research extends beyond the dimension of simply observing people and seeks to better understand those who belong to the culture. Ethnographic research looks at what may be considered ordinary or mundane to people residing within the certain culture. Both descriptive and interpretive accounts are included in how ethnographic inquiry is explored. Descriptive accounts are important, because they are so crucial to understanding what and how activities occur. Interpretive accounts in ethnographic inquiry determine the significance of what the researcher observes.

\section{Case Study}

There is no a single consensus on the definition of a case study (Yin, 2003). Generally speaking, a case study aims to explore and describe a setting where the researcher can gain more in-depth understanding of what he/she seeks. This study seeks to examine how non-verbal expression functions within communication during the language learning process, which requires in-depth description of these expressions. Yin (2003) described 
that a case study is an event and an individual of analysis. Such a study is an empirical inquiry relating to real life within its real life context. Much case study researches originated from ethnographic sites, such as those fields where participants are observed and data can be collected as well. In this case study, the field encompassing the desired research is a Korean language class that allows the researcher to participate in and observe the classroom, which is a main component of case study.

Case study research is a broad methodology and can be conducted through a range of research methods, both quantitative and qualitative. Choosing the method for data collection is linked to what seems appropriate both in the setting and in relation to the understandings the researcher hopes to generate. In this study, non-verbal expression is what is sought. This Korean program and Korean language learners' using non-verbal expressions are directly related to capturing the true meaning of non-verbal expressions in a specific setting. Through case study methodology, the research achieves thick description based on the realities the participants generate.

The "thick description" proposed by Patton (2002) can be explained by researchers to use narrative devices in an attempt to capture multiple realities and meanings within the settings. For instance, the researcher may want to count the number of times a teacher speaks to students and watch for variation in feedback behavior. Sometimes, it is useful to construct an inventory for this element of the research. If the researcher wants to count the number of times the language learners use body language and gestures of students and watch for variation in their learning process, the researcher will need to watch for whatever else maybe happening in the classroom. The researcher will need to offer thick description to relate information on the kind of components being observed. Based on these, case study is an effective methodology for exploring non-verbal expressions such as body language and gestures, which Korean language learners use while learning Korean.

\section{Participants}

There were six Korean language learners in the program. In this study, only two Korean language learners were examined. Since the research emphasizes the non-verbal expression of language learners, observing two learners carefully was an effective way to note detailed information regarding the two leaners' non-verbal expression. As such, the researchers focused on two learners, and observed their behaviors toward non-verbal expressive communication. The two participants are English-language speakers who were born in the United States of America. Pseudonyms are used to protect the identity of the two observed participants.

Kevin is an enthusiastic learner who tries to respond and participate actively. He has been married to his Korean wife, who works as a sociology professor in South Korea for three years. Kevin was a graduate student, majoring in language education, and he wishes to teach English to college-level students in South Korea after completing his Master degree program. His Korean language ability was the highest among all the Korean language learners in the program. He was able to construct basic skills of communication in Korean, such as greeting expression like 안녕하세요? (How are you?) and 저는케빈입니다 (I am Kevin). The Sunday Korean language program provided him an opportunity to improve and maintain his Korean language skills.

Jullie is a teenager whose grandmother is Korean. She decided to learn Korean since her grandmother asked her to enroll in the Korean program. She and her grandmother interact using English, but their communication in English is limited since her grandmother speaks broken English. She wants to learn more Korean to enable her to communicate with her grandmother more fluently, because she does not want to feel any barriers between her and her grandmother. Her spoken Korean language ability is very limited. However, 
her listening is the strongest area in her Korean abilities. Since she frequently listens to her grandmother speak Korean, her listening ability of Korean language was relatively higher than her speaking, reading, and writing skills. The instructor has worked voluntarily as a Korean language instructor in the Korean church for one year. The lesson plan and instructional activities were mainly derived from a textbook designed for the purpose of Korean language education for non-native Korean speakers.

\section{The Researchers}

In discussing qualitative research, Lincoln (1995) clearly explained the researchers' perspectives within the research and interpretation with the concept of positionality. Richardson and St. Pierre (2008) discussed the importance of the researcher being transparent about his relation to the research questions, subjects, and setting. Based on this, the researchers of this study played the role of observer with the objective view of analyzing what was observed. One researcher was foreign language learners who developed and instructed programs and curricula for English as a foreign language as well as Korean as a foreign language. Another Korean researcher, who was also teaching Korean, was a member of the Korean church and has a personal relationship with the Korean language learners. Teaching language in class were observed through the session when one Korean researcher was teaching Korean based on developed instructions in foreign language education. Through their works, they developed an understanding of the importance of an in-depth learning process of Korean language within foreign language education.

\section{Data Collection}

This study explored Korean-as-a-foreign language learners' non-verbal expressions in communicating in the target language by observing a Korean language program provided by a Korean church in a Southeastern state of the United States. The Korean language program has been open to non-Korean speakers, non-proficient Korean speakers who have Korean parent(s) but who are not fluent, and third generation Korean immigrant families who are interested in their grandparents' home language. According to the pastor of the Korean church, these Korean language classes are committed to not only a unique model of linguistic but also cultural immersion, which is best embodied by the Korean community and Korean language learning with a commitment to better communication with Koreans. The Korean language program gives learners experiences that encourage them to enhance their proficiency and the awareness of Korean culture.

The Korean programs offered by the Korean church consist of four levels of Korean language and culture courses over a 12-week session. The courses are designed to improve Korean language and cultural proficiency. Learners are asked to choose a course level based on their Korean language proficiency and are assigned based on an initial assessment. Each level offers four units of various topics. The program is basically open to anyone who is interested in learning Korean language. Before observing the class, we received approval to access the Korean program. Since we are members of the church, we emailed the pastor with personal introductions and described the purpose of observing classroom participation. Additionally, we asked the Korean instructor of the program if we could observe the language learners in her classroom. We informed the pastor and the instructor of our plan and the purpose of the observation. After we received consent from the pastor and the instructor, we were able to attend the class every sunday for three weeks in order to observe the learners' attitudes and behaviors toward the use of the non-verbal expression. The program we observed is the Korean language class for non-Korean speakers whose Korean abilities are so limited that they were novice-level Korean language 
learners. In class, they generally usedtheir mother language, English, as a part of their learning strategy. The Korean lesson wasprimarily composed of learning vocabulary and simple expressions as a way to apply the vocabulary they learned in framing simple sentences by switching the target word.

Pseudonums were used to protect the participants of this study from being embarrassed or offended in any way. The main focus of this ethnographic study was to identify the meaning of non-verbal expressions, such as body language, gesture, and facial expressions that learners manifest while learning Korean language. The non-verbal expression each learner made may relate to their personal preference or culture and may be unintentional. As such, the interpretation and analysis of the body language and gestures of the learners will be understood only from the perspective of the language learning process, excluding the cultural or individual aspect, with which the non-verbal expression may be implicated.

\section{Coding Process}

Strauss (1987) proposed the three primary purposes of the coding manual for qualitative research as follows:

1. To briefly discuss the functions of codes, coding, and analytic memo writing during the qualitative data collection and analytic processes;

2. To profile a selected yet diverse repertoire of coding methods generally applied in qualitative data analysis;

3. To provide readers sources, descriptions, examples, recommended applications, and exercises for coding and further analyzing qualitative data.

A code in qualitative inquiry was mostly displayed with a word or short phrases that could be attributed to what the researcher wanted to look for. Most codes are derived from language-based or visual data, such as interview transcripts, journals, documents, literature, artifacts, video, and participant observation field notes. The first stage of coding data ranged from a single word to a full sentence to several pages of text with a flow of an ongoing story. In the next coding stage, the coded data were further developed based on the exact same process using longer passages of text in order for a code to represent and capture a data's primary content and essence. The way in which Harry, Sturges, and Klingner (2005) coded and categorized the data of their ethnographic study regarding minorities in special education formed a foundation for how the data of our study should be coded and categorized. Their data were initially coded as classroom and categorized by materials, computers, and textbook. Another major category emerged labeled teacher skills with the subcategories instructional skills and management skills. The codes derived from our study are subsumed under the subcategories as follows:

1. Category: non-verbal expression;

2. Subcategory 1: body language;

(a) Code: shrugging;

(b) Code: tilting;

(c) Code: nodding.

3. Subcategory 2: facial expression;

(a) Code: closing eyes;

(b) Code: gazing;

(c) Code: winking;

(d) Data analysis. 
Data triangulation (Patton, 2002) was applied across previously mentioned data sources "to increase accuracy and credibility of findings" (p. 93). The researcher took a categorical approach to the analysis of data. Categories included inductive analysis (i.e., categories that emerge from the data) as well as descriptive and interpretive concepts. The research questions also drived analysis, looking for themes within the field notes and individual interviews. Categories of experience constituted units of analysis used in coding and triangulation of data, as well as individual interviews.

\section{Establishing Trustworthiness}

The issue of validity and reliability are central concepts to research, but differ in approach and terminology in qualitative and quantitative methods. The term "trustworthiness" is used in qualitative analysis instead of the conventional terms of validity and reliability used in quantitative inquiry. As Denzin and Lincoln (2008) explained, other concepts that are more appropriate to qualitative and interpretive research are necessary. Guba and Lincoln (1989) defined the process as achieving trustworthiness.

According to Guba and Lincoln (1989), credibility in qualitative research was equivalent to the concept of internal validity in quantitative and experimental research. Within experimental inquiry, researchers attempt to control a variable to evaluate the influence on another variable, in order to establish casual relationships among variables. Internal validity refers to the confidence that a researcher's results can be attributed to the control of a variable. The proposed study does not attempt to control such variables, and thus, must rely on the concept of credibility which is accomplished through analysis, description, and explanation of findings. Guba and Lincoln (1989) suggested that threats to validity within qualitative research could be addressed through various methods, such as prolonged engagement and persistent observation. A methodological strength of this study is that it was conducted over the span of three weeks with multiple methods of data collection and analysis.

Another criterion for strengthening trustworthiness within qualitative research is transferability (Guba \& Lincoln, 1989). Like the concept of external validity in quantitative inquiry, transferability is the ability to apply findings to other cases in order for the finding to be generalized to other people and settings. The goal of transferability is to provide thick description (Patton, 2002), so that the readers can understand the field studied and draw the study's meanings and significance based on the researcher' interpretation. Trustworthiness will be accomplished by providing thick description from the setting, participants, and the interviews throughout the study.

\section{Findings}

\section{Body Language of Language Learners}

Nodding was determined to be a part of discourse Kevin produced. For him, nodding was used to signal a degree of understanding Korean language. His nodding indicated he was positive in understanding what was asked in a classroom activity. During the learning activity of matching the correct pictures and Korean words, Kevin was quite competent, showing a frequent nodding behavior as an indicator of his ongoing comprehension of the activity. When he was able to provide an answer correctly in matching printed Korean words to the presented picture, he also nodded his head and responded with no hesitation (see Example 1).

\section{Example 1}

Instructor: (showing the picture of a book) 이게워 예요? [What is this?]

Kevin: (nodding while hearingthe question) 책. [A book.] 
Instructor: Can you say in a sentence?

Kevin: OK (nodding). 책이예요. [It is a book.]

Another frequently seen body language he presented was tilting his head. When negotiating Korean meaning to extend utterance to a more complex utterance, he often tilted his head and contemplated what to say before he responded (see Example 2).

\section{Example 2}

Instructor: (showing a picture of an umbrella) 케빈, 이게워 예요? (Kevin, what is this?)

Kevin: 어... 우산. [Um... umbrella.] (tilted his head) 우산은비... 내릴때... 사용해요. [Anumbrella is used... on a... rainy day.]

It appeared that the time spent searching for the correct verbal expression demanded a considerable amount of time for him in processing of his Korean language output with his head tilted. In Kevin's case, tilting behavior was seen as ongoing negotiation in forming the foreign language for the purpose of extending oral language. In the case of Jullie who has a Korean grandmother, body language was observed when Jullie tried to produce spoken Korean. She nodded and shrugged. Julie also nodded when she wanted to make sure she was using appropriate or correct Korean words. Julie used two distinct head movements. She would nod her head up and down to indicate a positive meaning toward her use of Korean and she would shake her head side-to-side to indicate negative meaning in her choice of the correct Korean word. When she nodded her head up and down, she was confident with the word she chose, when asked to match the correct Korean word to the picture. On the other hand, she was shaking her head side to side and she seemed to not be positive on her Korean word choice. Before producing spoken Korean, she shook her head which exemplified nodding head as a negative indicator. As a positive indicator, she would nod her head right after she received positive feedback from the instructor about her Korean production (see Example 3).

\section{Example 3}

Instructor: (holding a picture of a camera) 쥴리, 이게워예요? [Julie, what is this?]

Jullie: 카메라? [Camera?]

Instructor: (with thumb up) 잘했어요! [Good job!]

Jullie: (nodded up and down)

Shrugging represented another type of body language used by Julie as she responded to instruction. The researcher initially did not understand what the shrugging implied. Later, shrugging was interpreted as a neutral tool in expressing herself. It seemed like her shrugging behavior moderated her linguistic ability by informing the instructor that she was not able to generate further expression after shrugging (see Example 4).

\section{Example 4}

Instructor: (showing a picture of a doctor) 쥴리, 이게누구예요? [Julie, who is this?]

Jullie: (paused and shrugged)

Instructor: (making X hand gesture) 줄리, 모르겠어요? [Julie, you do not know?]

Jullie: (shrugged)

Instructor: (diverting the eye direction to other participants) 이게누구예요? [Who is this?] 
It was often observed that the instructor changed the topic during interactions with Julie when Julie shrugged her shoulders. It was perceived as if the instructor thought shrugging meant that Julie had disconnected from the interaction with her.

\section{Facial Expression of the Language Learners}

Kevin's closing his eyes was the most frequent type of non-verbal expression. Every time he spoke "Korean," he had to close his eyes and concentrated what he was saying. It appeared as if he was a sincere speaker. Related to his action of closing his eyes, an interesting fact was noticed during the interview with him upon the question, "Do you sometimes experience that Korean is a difficult language to speak?" His responsed, "I have never experienced that in the domain, in the mode of speech, I am always nervous or not confident in my speaking ability. But in my reading and listening ability, I can recall a specific moment where I felt enjoyment of learning Korean." He often closed eyes when speaking Korean. His non-verbal reaction was related to his thoughts about the competence of his speech.

The gazing behavior as non-verbal communication between Kevin and Julie are distinct. The difference in gazing behaviors between the two participants was connected with what Julie and Kevin looked at. While Kevin looked directly at the teacher, Julie looked at the teacher and other objects such as a notebook much more than Kevin. The gaze behaviors demonstrated a significant difference between the two participants on oral language performance. Kevin more often gazed at the instructor when he was confused and ambiguous about what he was asked to do than Julie. Julie took some seconds or minutes to gaze at the instructor and then looked at her notebook longer. It looked more likely she was negotiating what to say while her eyes were fixed on the notebook. Fixation of eyes on the notebook signaled that she was seeking the appropriate Korean expression from what she learned. While Julie was struggling to look for the proper words or expression, the instructor encouraged her by waiting for her response with a pleasant tone of voice telling to her to take a time (see Example 5).

\section{Example 5}

Instructor: (with a flashcard of car) 이단어는어떻게읽나요? [How do you pronounce this word?]

Jullie: (mumbled and gazed)

Instructor: It is a difficult word. We learned this word last time.

Jullie: (gazed at her notebook).

Instructor: 자... 자로시자하죠... [Start with ja... ja...]

Jullie: ... 자동차. [Jadongcha.]

Instructor: 잘했어요! [Good job!]

With the support of the instructor, Julie made another attempt to generate Korean language. During this moment, enjoyable tension was embedded in the classroom and other peers also tried to seek the correct answer along with the Julie's effort.

A distinct facial expression only Julie expressed was wink. She was a bright and cheerful girl. It was seen that she sometimes winked to the instructor and the peer in her English speaking as well as in her Korean learning. When she gave winks to people during the interaction with the peers and the instructor, it created a friendly learning environment. Within the friendly environment, she felt herself a little more competent in learning Korean. Her winking action was likely to occur at anytime. It was difficult to connect the action to 
language learning, because it came at anytime in any situation. However, one sure thing about her wink was that it created friendlier learning environment for the instructor and her peers. From her facial expression, it appeared Julie was enjoying learning Korean language.

\section{Non-Verbal Expression of the Language Instructor}

During the lesson, one gesture the instructor used quite a bit was nodding. When she understood or when she heard something when students successfully reproduced the target form or the target use of vocabulary or complete some others that she desired for them, she did a lot of nodding to indicate that the students performed successfully. The instructor's nodding behavior encouraged the learners to complete the language expressions that the learners were intended to produce (see Examples $6 \& 7$ ).

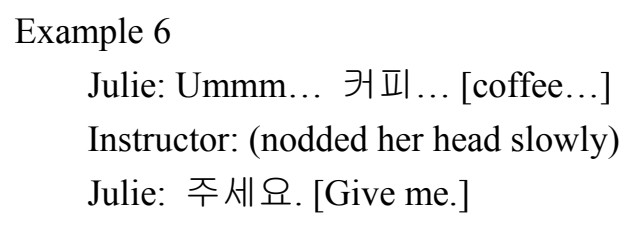

Hand gesture with thumb(s) up was another communicative tool for the instructor. During the interview with the instructor, she admitted to using a lot of hand gestures such as thumb(s) up intentionally as indicating the learners' oral performance was good or less good. She believed that adopting hand gestures in the discourse was necessary and purposeful for those who had limited vocabularies or lacked listening ability. Another purpose of implementing non-verbal expressions in her lesson conveyed other types of opposite concepts: like $v s$. dislike, good $v s$. bad, and positive $v s$. negative. Through the implementation of these non-verbal expressions for novice-level language speakers, learners could produce the language with the support of non-verbal cues conveyed by their instructor.

\section{Limitation}

The participants in this study are chosen in accordance with the purpose of this study. The participants are all non-Korean speakers, excluding other learner groups, such as Korean children who are learning Korean literacy. The participants of this study are novice-level Korean language learners whose mother language is English and this program is their first experience in learning Korean. There are time constraints for this study. This study was conducted for three weeks. This length of time to examine non-verbal expression may be insufficient and limited the generalizability of the study's findings.

\section{Conclusions}

The findings from this study indicate that non-verbal expression of language learners at a low-proficiency level revealed a significant aspect as does the claims that language learners, particularly, novice language learners with limited level of proficiency, need non-verbal expressions as a meaningful tool for communication in conveying linguistic meanings of the target language (Kiernan, 2013). Body language and facial expression 
expressed by the language learners convey implicit communicative meanings. Language learners' body language and facial expression shown in the foreign language learning process indicate their learning process while negotiating and seeking the appropriate and correct expression of the target language. Sending and receiving of body language contribute to communicating with each other in terms of functioning as a linguistic medium. In this finding, non-verbal expressions are verified as a necessary communicative tool for the language learners. Non-verbal expressions should be considered as meaningful in the language classroom and used as an indicator of language learners' comprehension of the target language.

Non-verbal expressions should be understood and utilized by language instructors in order to create a learning environment that encourages learnersto produce the target language. Exchanging non-verbal expressions with learners enables language instructors to respond to the learners promptly by understanding the meanings of non-verbal expressions. As language instructors recognize the meanings of non-verbal expressions generated by language learners, they are able to link the non-verbal cues to meaningful language instructions. Additionally, by being aware of non-verbal expressions produced by language learners, instructors respond promptly using appropriate non-verbal cues for those who have limited language abilities.

An important aspect of non-verbal cues, such as body language and gestures concerning some foreign language learners, is that they have not yet developed the verbal proficiency to address their thoughts and opinions when speaking the target language. Consequently, the reliance on non-verbal communication of low-proficiency level language learners may be even greater and non-verbal cues between language learners and speakers of the target language may have a more important function for communicating in the process of language learning than situations where more fluent learners communicate with interlocutors.

In summary, in this study, non-verbal expressions, such as body language and gestures demonstrated a meaningful function as a medium in learning the target language. Sending and receiving non-verbal expressions between the instructor and the language learners revealed significant roles for non-verbal expressions, which can be interpreted as alternative linguistic meanings for low-proficient language learners. Understanding non-verbal messages enables the instructor and the learners to be engaged in the language process with the learning environment embedded with positive and friendly non-verbal messages. Therefore, non-verbal expressions exchanged between language learners and instructors should be understood and used as a medium to communicate with each other and assist the learners to be engaged consistently in foreign language learning.

\section{References}

Albers, D. (2001). Non-verbal immediacy in the classroom. Retrieved from http://clearinghouse.mwsc.edu/manuscripts Denzin, N. K., \& Lincoln, Y. S. (2008). Strategies of qualitative inquiry (3rd ed). Los Angeles, C.A.: Sage Publications. Eisenberg, A. M., \& Smith, R. R. (1971). Nonverbal communication. New York, N.Y.: The Bobbs-Merrill Company, Inc.. Eryilmaz, D., \& Darn, S. (2006). Non-verbal communication. Retrieved from https://www.teachingenglish.org.uk/article/nonverbal-communication

Guba, E., \& Lincoln, Y. (1989). Fourth generation evaluation. Newbury Park, C.A.: Sage Publications Inc..

Haager, D., \& Klingner, J. K. (2005). Differentiating instruction in inclusive classrooms: The special educators' guide. Boston, M.A.: Allyn \& Bacon.

Harry, B., Sturges, K. M., \& Klingner, J. K. (2005). Mapping the process: An exemplar of process and challenge in grounded theory analysis. Educational Researcher, 34(2), 3-13. Retrieved April 28, 2005, from http://www.aera.net/uploadedFiles/ Publications/Journals/Educational_Researcher/ 3402/3402_Harry.pdf

Kiernan, E. (2013). Oral communication: Presentations and interviews. In Communicating for success (pp. 194-222). Sydney, Australia: Pearson Australia.

Kodakos, A., \& Polemikos, N. (2000). Nonverbal communication in kindergarten. Athens, Greece: Ellinika Grammata. 
Koper, R. J. (1984). Non-verbal and relational communication associated with reticence. Human Communication Research, 10(4), 601-626.

Lee, J., \& Kim H.Y. (2008). Korean heritage language education in the United States: The current state, opportunities, and possibilities. Heritage Language Journal, 6 (2), 1-20.

Lincoln, Y. S. (1995). Emerging criteria for quality in qualitative and interpretive research. Qualitative Inquiry, 1(3), $275-289$.

Patton, M. Q. (2002). Qualitative research \& evaluation methods. Thousand Oaks, C.A.: Sage.

Richardson, L., \& St. Pierre, E. (2008). A method of inquiry. Collecting and Interpreting Qualitative Materials, 3(4), 473.

Ryan, C. (2013). Language use in the United States: 2011. American Community Survey Reports, 22, 1-16.

Sprinthall, N. A. (1994). Counseling and social role taking: Promoting moral and ego development. In J. R. Rest, \& D. Narvaez (Eds.), Moral development in the professions: Psychology and applied ethics (pp. 85-99). Hillsdale, N.J.: Lawrence Erlbaum. Strauss, A. (1987). Qualitative analysis for social scientists. New York, N.Y.: Cambridge University Press.

Yin, R. K. (2003). Applications of case study research (2nd ed.). Thousand Oaks, C.A.: Sage. 